\title{
Simulation and Analysis of Cavitating Flow in the Draft Tube of the Francis Turbine with Splitter Blades at Off-Design Condition
}

\author{
CongTrieu TRAN, Bin Jl, Xinping LONG
}

\begin{abstract}
Hydraulic plants are required to operate with wider operating range to cover the variants of power outputs into the electrical grid. Although there have been many studies of off-design conditions, studies of cavitating draft tube vortices at the Francis turbine with splitter blades are limited, and the cavitating property is not yet well comprehended. This study presents a prediction of the cavitating characteristics in the Francis-99 draft tube obtained by numerical analysis using the Zwart mass transfer model and shear-stress transport (SST) model. The shape characteristics of two types of cavitating vortex rope (spiral and columnar) and its influence on the cavitation development in the runner blades are analyzed. The link between cavitation with the vorticity is further highlighted by the vorticity transport equation (VTE). The result indicates that the runner cavitating is symmetric for both types of cavitating vortex ropes, and cavitation is significantly improved when a runner with splitter blade is used.
\end{abstract}

Keyword: Cavitating vortex rope; Francis turbine; numerical simulation; off-design condition; splitter blades

\section{INTRODUCTION}

Hydraulic turbines are crucial components in energy conversion technologies as they play a major role in both primary and secondary load balancing tasks and preserving grid stability. Nevertheless, the frequent changes in power generation by renewable energy resources directly impact the required operating range of the hydro units. Extending the operating range of Francis turbine increases the working time at off-design load (high load (HL) and part load (PL)) which results in complex flow phenomena like cavitation and pressure fluctuations in the draft tube that can lead to dangerous output power swings [1]. Jing Y. et al. [2, 3] used the computational fluid dynamic (CFD) technology with the Large Eddy Simulation turbulence model to simulate cavitating flow in a high head Francis turbine. They found that the cavitation region on the runner blades for HL and PL conditions corresponding were symmetric and axisymmetric.

Many studies have been performed to improve the characteristics of cavitation, control and reduce its effect, and to consider two splitter-blade-fitted runners, which can improve the cavitation characteristics and the load distribution on the runner blades, decrease pressure pulsation [4]. Kergourlay G. et al. [5] found that when the impeller was added splitter blades, the vibrating acceleration level is reduced. Hongming Zhang et al. [6] used OpenFOAM $\AA$ code to simulate cavitating flow in the runner with splitter blades of a Francis turbine at PL operation, and the cavitation on the runner blades was observed. Recently, the Francis-99 workshop took place for the discussion of CFD techniques with application to a Francis turbine with splitter blades, which was called Francis-99 turbine [7, 8] and reviewed by Trivedi C. et al. [9]. The researchers attempted to analysis the pressure fluctuations in the rotating part and the non-rotating part. These studies are helpful for a deeper understanding of the pressure oscillations mechanisms in a Francis turbine with splitter blades [10-12]. However, more work is needed to further demonstrate the cavitating rope on the Francis-99 draft tube core and the improvement of cavitating characteristics in the runner with splitter blades. Therefore, this work focuses on the investigation of the dynamics of the processing cavitating vortex core on the Francis-99 draft tube. The Zwart et al. model [13] and SST model [14] were used to simulate the cavitating development at critical, and inception in the draft tube under PL and HL operating points and the cavitating vortex ropes are captured, and its influence also analyzed. In addition, the link between the vorticities source and vapor volume fraction is also highlighted by VTE.

\section{MATHEMATICAL METHOD}

It is compulsory to consider the runner when simulating hydraulic turbines. Thus, to model the runner rotation, the rotating reference frame was used. In addition, the two phases are needed to be considered when simulating cavitating flow.

\subsection{Governing Equations and Cavitation Model}

The governing equations to describe the liquid-vapour two phases flow are the mass conservation equation, the conservation momentum equation and the transport-based equation under cavitation condition in a rotating reference frame with the angular speed $\Omega$ and absolute velocities:

$$
\begin{aligned}
& \frac{\partial \rho_{\mathrm{m}}}{\partial t}+\frac{\partial\left(\rho_{\mathrm{m}} u_{i}\right)}{\partial x_{j}}=0 \\
& \frac{\partial\left(\rho_{\mathrm{m}} u_{i}\right)}{\partial t}+\frac{\partial\left(\rho_{\mathrm{m}} u_{i} u_{i}^{\mathrm{r}}\right)}{\partial x_{j}}=-\frac{\partial p}{\partial x_{j}}+\frac{\partial}{\partial x_{j}}\left(\tau_{i j}^{\mathrm{n}}+\tau_{i j}^{\mathrm{t}}\right)-\rho \varepsilon_{i j k} \Omega_{j} u_{k} \\
& \frac{\partial\left(\alpha_{\mathrm{v}} \rho_{\mathrm{v}}\right)}{\partial t}+\frac{\partial\left(\alpha_{\mathrm{v}} \rho_{\mathrm{v}}\right)}{\partial x_{j}}=R_{\mathrm{e}}-R_{\mathrm{c}}
\end{aligned}
$$

Where $u_{i}$ and $u_{i}^{\mathrm{r}}$ denote the absolute velocity and relative velocity components; $\rho_{\mathrm{m}}$ and $\rho_{\mathrm{v}}$ are the mixture density and density of vapor phase; $p$ represents the mixture pressure; $\Omega$ is the angular velocity of runner rotation; $\varepsilon_{i j k}$ is called Levi-Civita symbol; $\tau_{i j}^{\mathrm{t}}$ and $\tau_{i j}^{\mathrm{n}}$ are the turbulent stress tensor and the viscous stress tensor, respectively; $\alpha_{\mathrm{V}}$ represents the volume fraction of vapor phase; $R_{\mathrm{e}}$ and $R_{\mathrm{c}}$ denote the effects of evaporation and condensation during phase change. 
In this study, the Zwart mass transfer model [9] was used. The source terms $R_{\mathrm{e}}$ and $R_{\mathrm{c}}$ in the Eq. (3) can be obtained by:

$$
\begin{aligned}
& R_{\mathrm{e}}=F_{\mathrm{vap}} \frac{3 \alpha_{\mathrm{nuc}}\left(1-\alpha_{\mathrm{v}}\right)}{R_{\mathrm{B}}} \sqrt{\frac{2}{3} \frac{p_{\mathrm{v}}-p}{\rho_{\mathrm{l}}}}, \text { if } p<p_{\mathrm{v}} \\
& R_{\mathrm{c}}=F_{\text {con }} \frac{3 \alpha_{\mathrm{v}} \rho_{\mathrm{v}}}{R_{\mathrm{B}}} \sqrt{\frac{2}{3} \frac{p-p_{\mathrm{v}}}{\rho_{\mathrm{l}}}}, \text { if } p>p_{\mathrm{v}}
\end{aligned}
$$

where $\alpha_{\text {nuc }}$ represents the volume fraction of the nucleation site; $p_{\mathrm{v}}$ represents the vapor pressure; $F_{\text {con }}$ and $F_{\text {vap }}$ stand in empirical coefficients for the condensation and evaporation processes. The following recommended model parameters are used in this study: $F_{\text {con }}=0.01, F_{\text {vap }}=50, R_{\mathrm{B}}$ $=1 \mu \mathrm{m}$ and $\alpha_{\text {nuc }}=5 \mathrm{E}-4$ [13].

Although simulations have been performed with $k-\varepsilon$, SST, SAS, RSM, LES, DES, etc., the SST is the most widely used and has become a standard for turbo machinery [15-19].In this work, all simulations, including steady and unsteady are performed with the SST turbulence model.

\subsection{Numerical Setup}

The numerical configurations were for the Francis-99 turbine model. Besides the runner that includes 15 long and 15 splitter blades, the turbine contains 14 stay vanes, 28 guide vanes, and a drat tube (Fig. 1). TheFrancis-99 turbine numerical grid uses the ICEM files provided by [7] and created with ANSYS ICEM CFD. The mesh density for the full turbine model at the best efficiency point (BEP) was about 20 million elements. The quality and mesh independency were reported by Trivedi C. et al. [20, 21] and Goyal R. et al. [22], which corresponded to the normal industrial standard.

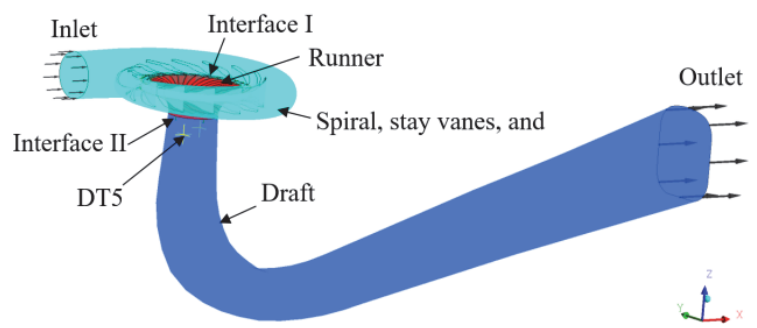

Figure 1 The three simulation domains of Francis-99 turbine with two interfaces: interface I, connecting the runner with guide vanes domain; interface II, connecting draft tube with runner domain.

In this study, the simulations of the turbine model were played in two steps to include steady and unsteady simulations. We performed the unsteady simulations with the initial field obtained from the steady simulations results.

General Grid Interfaces (GGI) connect stationary domains (guide vanes and elbow type draft tube) to the rotating domain (runner).

In this study, the inlet boundary was given by the mass flow, and the outlet static pressures were assigned according to the cavitation number $\sigma$ :

$$
\sigma=\frac{1}{H}\left(\frac{p_{\text {out }}}{\rho g}-h_{\mathrm{s}}-\frac{p_{\mathrm{v}}}{\rho g}\right)
$$

Here $H$ represents the net head; $p_{\mathrm{v}}$ and $p_{\text {out }}$ are the saturated pressure $(3170 \mathrm{~Pa})$ and outlet static pressure of the draft tube; $h_{\mathrm{s}}$ means the suction height.

To investigate the cavitating vortex rope, the unsteady simulation was run for ten rotations of the runner where total computation time was $1.8 \mathrm{~s}$. The time step was set as $t=5 \mathrm{E}-4 \mathrm{~s}\left(1^{\circ}\right.$ per time step $)$. The convergence criteria were set to a root-mean-square (RMS) value less than $10 \mathrm{E}-5$.

\section{RESULTS AND ANALYSES 3.1 Validation}

For convenience to validate the simulation model used in this study, Tab. 1 shows a comparison of torque obtained by the SST and experiment [7]. The numerical torque is 465 Nm (under PL), $706 \mathrm{Nm}$ (under BEP), and $820 \mathrm{Nm}$ (under HL) higher than the experimental torque, and the ration of numerical torque to experimental torque was $10 \%, 14 \%$, and $10 \%$, respectively. The result is consistent with numerical torque studied by Gavrilov A. [17] with the same model Francis-99. Consequently, the mesh quality and flow separation can cause the torque calculation inaccuracy in the simulation.

Table 1 Torque on the runner, $\mathrm{Nm}$ (discrepancy \%)

\begin{tabular}{|l|c|c|c|}
\hline & PL & BEP & HL \\
\hline SST in this study & $465(10 \%)$ & $706(14 \%)$ & $820(10 \%)$ \\
\hline SST [17] & $487(16 \%)$ & $703(13 \%)$ & $835(12 \%)$ \\
\hline Experiment [7] & $421(0 \%)$ & $621(0 \%)$ & $744(0 \%)$ \\
\hline
\end{tabular}

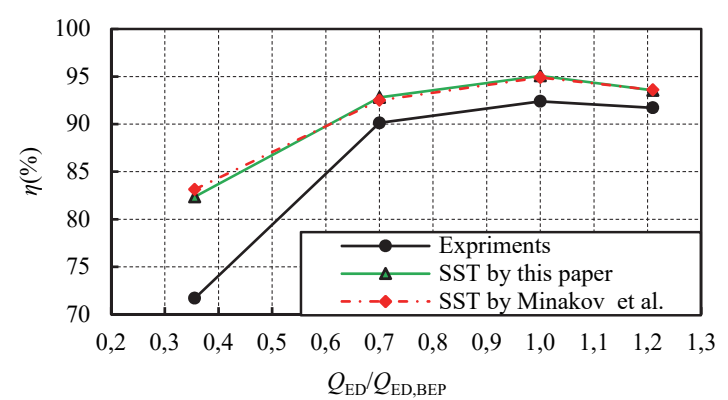

Figure 2 Comparison of experimental and numerical hydraulic efficiencies at four operating points.

Fig. 2 shows the comparisons of the efficiencies of the steady simulations for min load (ML), PL, BEP, and HL operating points between the numerical and experimental results. The highest and smallest discrepancies between the experimental and numerical (SST) efficiencies are 10.66\% and $1.83 \%$, which are observed at the ML and HL operating point. The numerical results are also in agreement with studies by Minakov et al. [19] and Trivedi C. et al. [20].

Figs. 4-6 show the comparison of the calculated and experimental vertical velocity profiles along two lines 1 and 2 (see Fig. 3). As can be seen, under PL and HL operating points (Figs. 4 and 5) the magnitude of the vertical velocity is significantly smaller than under the BEP (Fig. 6). Figs. 4 and 5 show that under the PL and HL conditions the flow nearest the draft tube core is nearly reversed. Furthermore, under the PL condition, the simulation model gives the discrepancy of vertical velocity 
with the experimental result at the draft tube core, as shown in Figs. 4(a) and 4(b). The simulation profiles have a reverse zone near the draft tube core, but the experimental does not show this. Therefore, the simulation vertical velocity is higher than the experimental, which is due to the mass velocity being significantly low for the PL condition. The vertical velocity for all operating conditions is in good agreement between the steady simulation and experimental results with small deviations.

The above comparisons with the simulation results show a good agreement with the experimental, the reliability of the numerical model is validated.

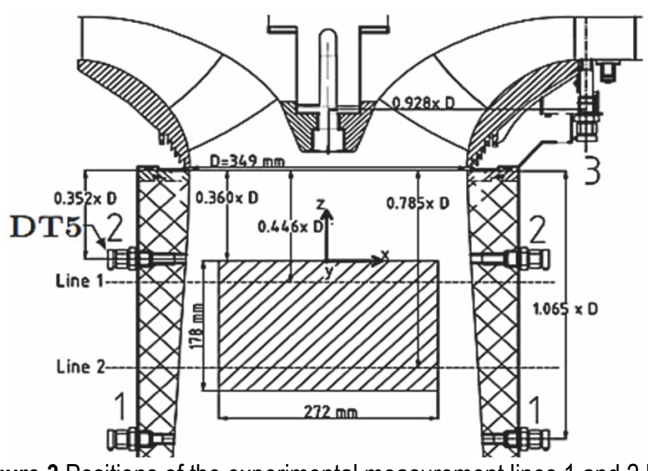

Figure 3 Positions of the experimental measurement lines 1 and 2 [20]
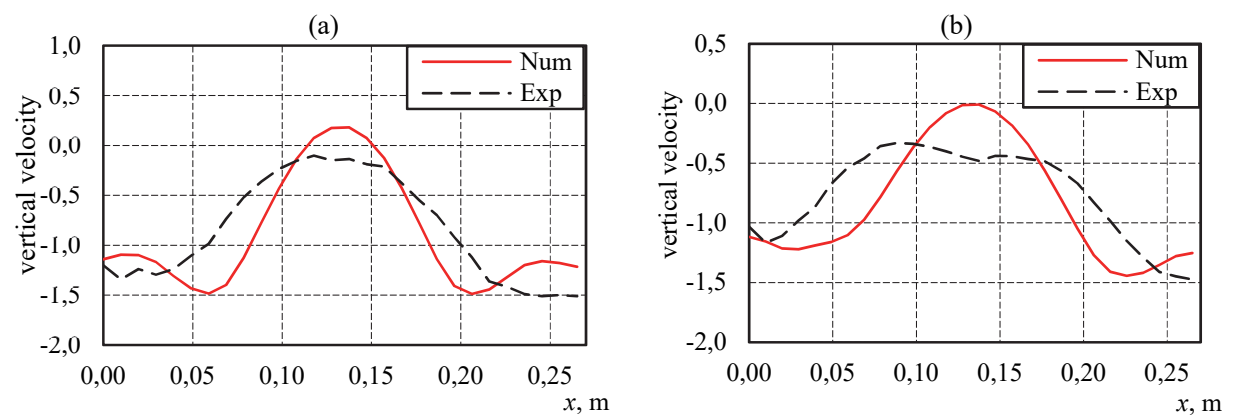

Figure 4 Vertical component of the velocity in line $1(a)$ and line 2(b) for PL regime.
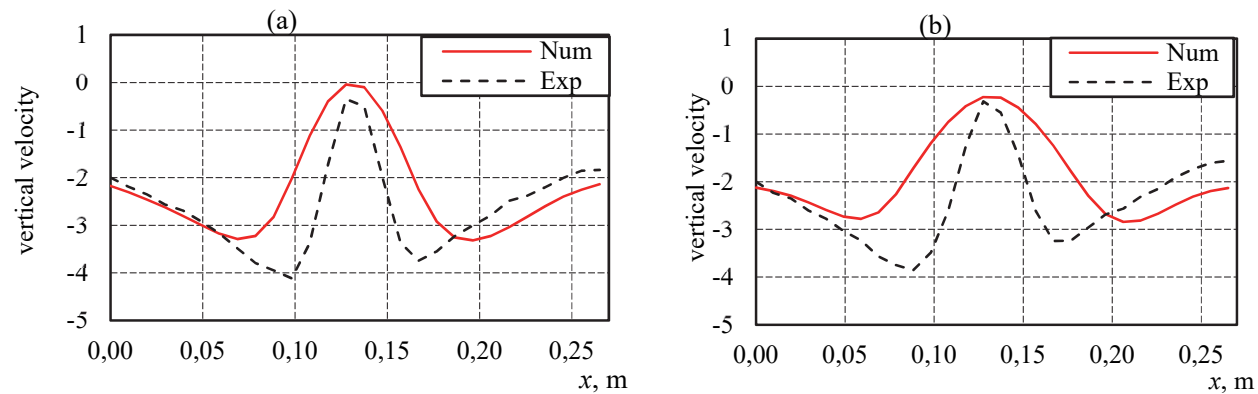

Figure 5 Vertical component of the velocity in line $1(a)$ and line 2(b) for HL regime.
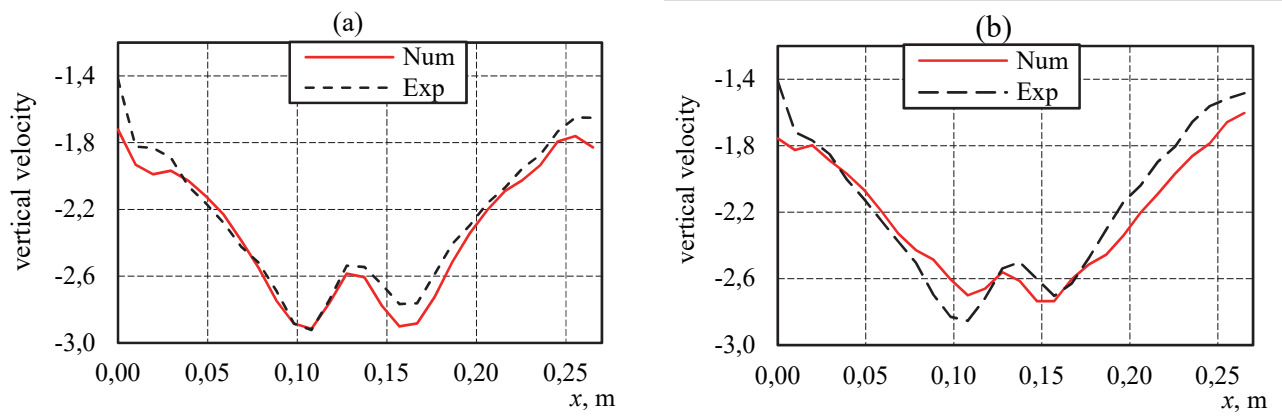

Figure 6 Vertical component of the velocity in line 1(a) and line 2(b) for BEP regime.

\subsection{Characteristics of Cavitating Vortex Ropes}

To promote the development of cavitation and make the vortex core visible, a reduction in the outlet static pressure is usually used to decrease cavitation number of a Francis turbine. According to IEC 60193 standard, the cavitation number $\sigma$, corresponding to the $1 \%$ drop in efficiency was defined as the critical cavitation number $\left(\sigma_{\mathrm{c}}\right)$. Therefore, in this study under HL and PL operating points, the critical cavitation numbers were calculated as 0.033 and 0.01 , respectively.
As respected, the cavitation number $\sigma$ decreases corresponding to the proliferation of the cavitation volume and the cavitation flow can be visualized by a vapor volume fraction value iso-surface. Figs. 7 and 8 show the simulation results for different cavitation numbers (inception and critical) under PL and HL operating regimes, respectively. Figs. 7(a), 7(b), 8(a), and 8(b) show the cavitation visualization of one typical cycle based on the $\alpha=10 \%$ iso-surface of vapor volume. Figs. 7(c) and 8 (c) show the vortex rope structures visualized by $Q$ criterion [23]. As shown in Figs. 7(b), 7(c), 8(b), and 8(c), the cavitating vortex rope moves downstream and 
collapses, but the vortex rope is still extending into downstream of the draft tube. These pictures show an association of the cavitating rope and vortex in the draft tube.

For inception cavitation number, cavitation rope can be observed near in the runner outlet and emerged under the hub of the runner with the short length and small diameter (Figs. 7(a) and 8(a)). When the cavitation number was reduced to the critical cavitation number, the length and diameter of the cavitating rope were significantly longer and thicker, and the cavitating rope extended downstream as shown in Figs. 7(b) and 8(b). Furthermore, for critical cavitation, the cavitating rope structure at near runner outlet was straight cylinder before changes and became a spiral shape and columnar shape at PL and HL operating points, respectively. Besides, due to the unstable behavior of the vapor volume (grow and suddenly collapse), the diameter suddenly decreased at near the tail of cavitating rope. These results are also consistent with the experimental observation by Kobro et al. [24] thus suggesting that the shape characteristics of the vortex rope at off-design conditions is well predicted.

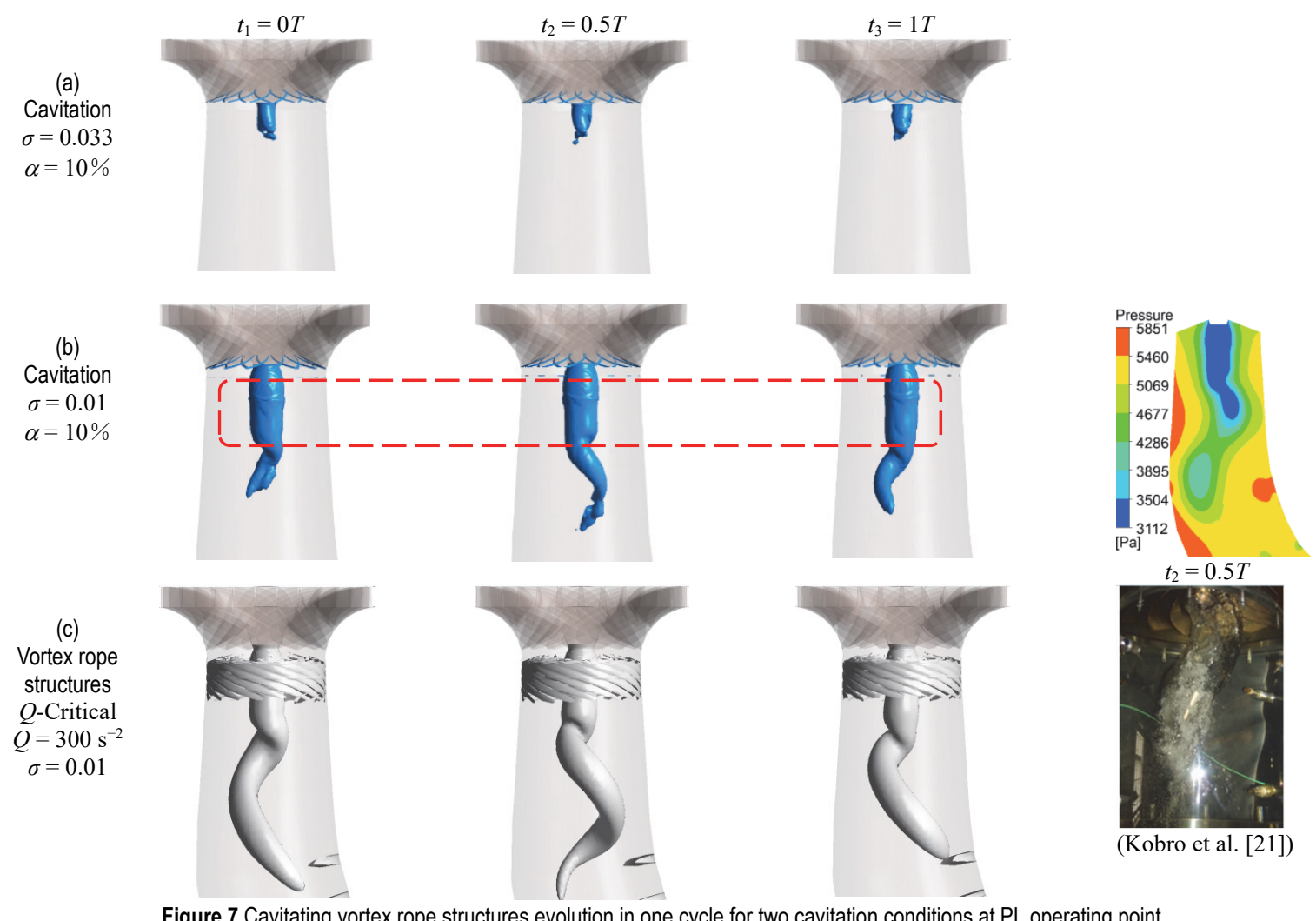

To further understand the interaction mechanism between cavitating flow and vortex production in the draft tube, the VTE was employed to analyze cavitating flows as follows:

$$
\frac{\mathrm{d} \omega}{\mathrm{d} t}=(\omega \cdot \nabla) V-\omega(\nabla \cdot V)+\frac{\nabla \rho_{\mathrm{m}} \times \nabla p}{\rho_{\mathrm{m}}^{2}}+\frac{1}{R_{e}}\left(\nabla^{2} \cdot \omega\right)
$$

where $V$ is the velocity, $\omega$ represents the vorticity, and $R_{\mathrm{e}}$ is the Reynolds number.

On the right-hand side of Eq. (7), the vorticity production in the fluid is attributed to four parts. The first term, i.e., $(\omega \cdot \nabla) V$, is called the vortex stretching by the swirling and stretching of the flow vorticity. The second term, i.e., $\omega(\nabla \cdot V)$, represents the vortex dilatation which is due to the effect of the fluid compressibility to the vorticity. The third term, i.e., $\nabla \rho_{\mathrm{m}} \times \nabla p / \rho_{\mathrm{m}}^{2}$, means the baroclinic torque due to the misaligned density and pressure gradients then is nonzero in the vapor zone. The last term, i.e., $\left(1 / R_{\mathrm{e}}\right)\left(\nabla^{2} \cdot \omega\right)$, indicates the effect of viscous diffusion, and due to the effect it is significantly smaller than the other terms and can be ignored $[25,26]$.
From Eq. (7), we can obtain the influence of vortex production on cavitation on the mid-plane of the draft tube $(y=0)$ as follows:

$$
\begin{aligned}
& \frac{\mathrm{d} \omega_{y}}{\mathrm{~d} t}=[(\omega \cdot \nabla) V]_{y}-[\omega(\nabla \cdot V)]_{y}+ \\
& +\left[\frac{\nabla \rho_{\mathrm{m}} \times \nabla p}{\rho_{\mathrm{m}}^{2}}\right]_{y}+\left[\frac{1}{R_{e}}\left(\nabla^{2} \cdot \omega\right)\right]_{y} \\
& {[(\omega \cdot \nabla) V]_{y}=\omega_{x} \frac{\partial V_{y}}{\partial x}+\omega_{y} \frac{\partial V_{y}}{\partial y}+\omega_{z} \frac{\partial V_{y}}{\partial z}} \\
& {[(\omega \cdot \nabla) V]_{y}=\omega_{y}\left(\frac{\partial V_{x}}{\partial x}+\frac{\partial V_{y}}{\partial y}+\frac{\partial V_{z}}{\partial z}\right)} \\
& {\left[\frac{\nabla \rho_{\mathrm{m}} \times \nabla p}{\rho_{\mathrm{m}}^{2}}\right]_{y}=\left(\frac{\rho_{\mathrm{l}}-\rho_{\mathrm{v}}}{\rho_{\mathrm{m}}^{2}}\right)\left(\frac{\partial \alpha_{\mathrm{v}}}{\partial z} \frac{\partial p}{\partial x}-\frac{\partial \alpha_{\mathrm{v}}}{\partial x} \frac{\partial p}{\partial z}\right)}
\end{aligned}
$$


(a)

Cavitation

$\sigma=0.051$

$\alpha=10 \%$

(b)

Cavitation
$\sigma=0.033$

$\alpha=10 \%$

(c)

Vortex rope

structures

$Q$-Critical

$Q=600 \mathrm{~s}^{-2}$

$\sigma=0.033$
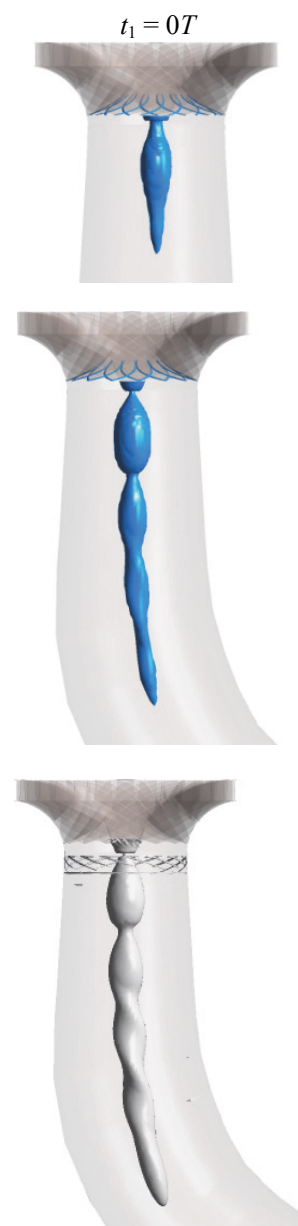

$t_{2}=0.5 T$
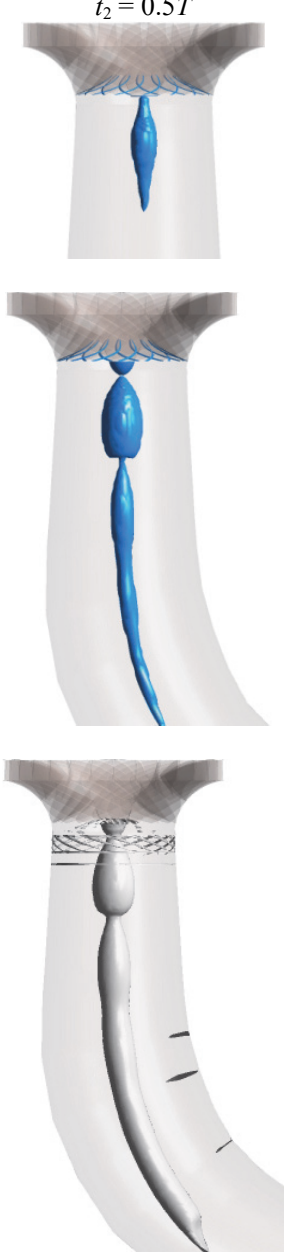
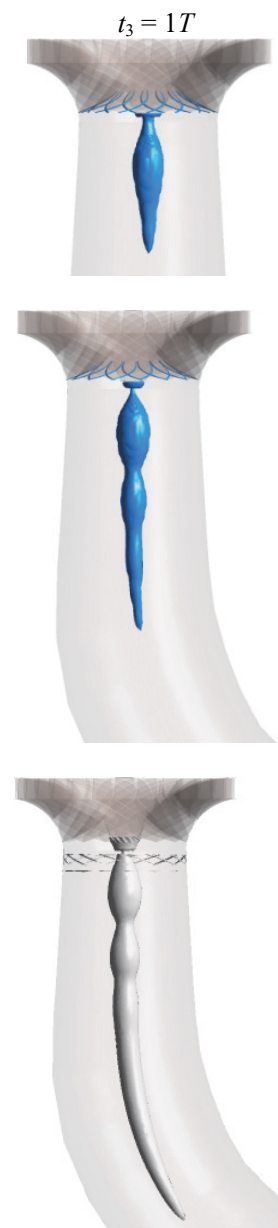
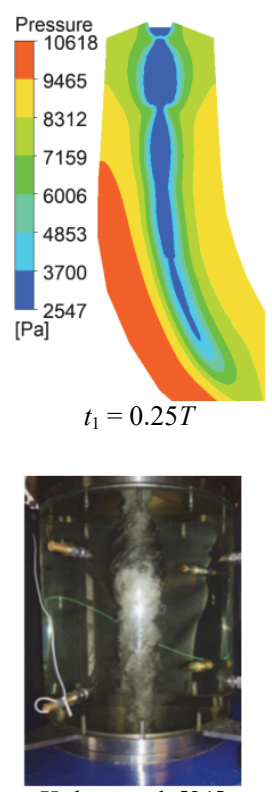

Kobro et al. [21]

Figure 8 Cavitating vortex rope structures evolution in one cycle for two cavitation conditions at HL operating point.

(a)

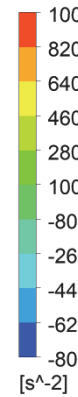

1000
-820
640
-460
-280
-100
-80
-260
-440
-620
-800
$\left[\mathrm{~s}^{\wedge}-2\right]$

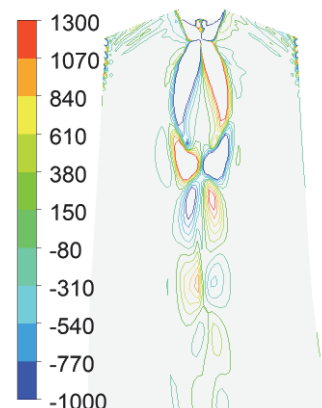

$\left[\mathbf{s}^{\wedge}-2\right]$
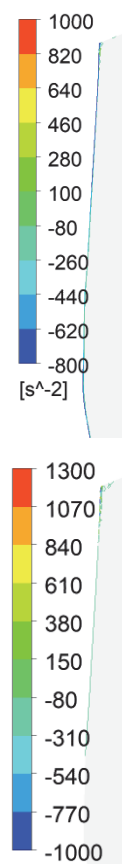

[s^-2]

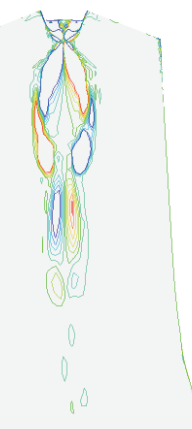

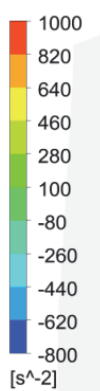

(c)
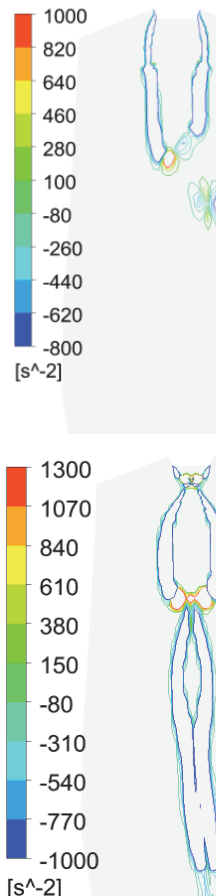

(d)

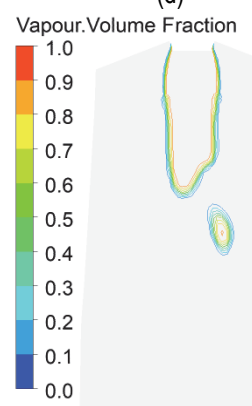

Vapour.Volume Fraction

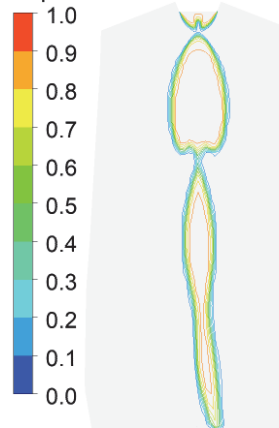

Figure 9 Contour line of vortex stretching (a), vortex dilation (b), baroclinic torque(c), and vapor volume fraction (d) in plane XZ of draft tube under PL (above) and HL (below) operating conditions. 
Fig. 9 compares the contours of the vorticity distribution of the vortex stretching (Fig. 9(a)), vortex dilation (Fig. 9(b)), baroclinic torque (Fig. 9(c)), with cavitation development (Fig. 9(d)) on the plane $\mathrm{XZ}$ at one typical instant in the draft tube. It can be observed from Fig. 9 that the variation of vorticity distribution is strongly associated with the vapor volume fraction. Fig. 9(a) and 9(b) indicate those two terms: the vortex stretching and play a dominant role for vorticity generation in the draft tube. As shown in Fig. 9(c), the baroclinic torque term is much weaker than other terms in Eq. 8. The vortex dilatation and baroclinic torque term only happened at the zones of high vapor volume fraction. The picture indicates that the almost vorticities were produced by vortex stretching term. Final, the vortex stretching and dilation term produced a strong vortex rope, and vorticity distribution seems symmetrical at near runner outlet in draft tube inlet zone with the splitter blades runner.

\subsection{Effect of Cavitating Vortex Rope with Cavitation on the Runner Blades}

Fig. 10 shows the cavitation on the runner under offdesign load. It can be seen that under both the HL and PL operating points, the cavity zone on different blades was almost axisymmetric.This result was different from that for the splitter blades runner and traditional runner, as shown in Fig. 11. For the conventional runner, in the paper of Jing Y. et al. [3], there is asymmetrical cavitation on the runner blades for PL operating conditions. Unlike the traditional runner, the asymmetrical phenomena seemed to be more mitigated with the splitter blades runner. This is due to the cavitating vortex rope at near runner outlet regime that is cylinder-shaped and extended in to downstream before its diameter suddenly reduced and became a spiral-shape, as shown in Fig. 10 (below). In addition, the pressure in the runner varied by the effect of cavitating rope evolution on the draft tube. Therefore, the runner pressure distribution changes symmetrically, and cavity zones on each blade were little changed with cavitating rope oscillation.

Fig. 12 shows the relationship between the vapor volume in the draft tube and the runner over time in one vortex rope cycle under HL and PL operating points. It can be observed that the vapor volume changes a lot in one period. The tendency of vapor volume oscillation in the draft tube and the runner is remarkably uniform. Therefore, there is a strong correlation between cavity dynamic in the draft tube and runner.
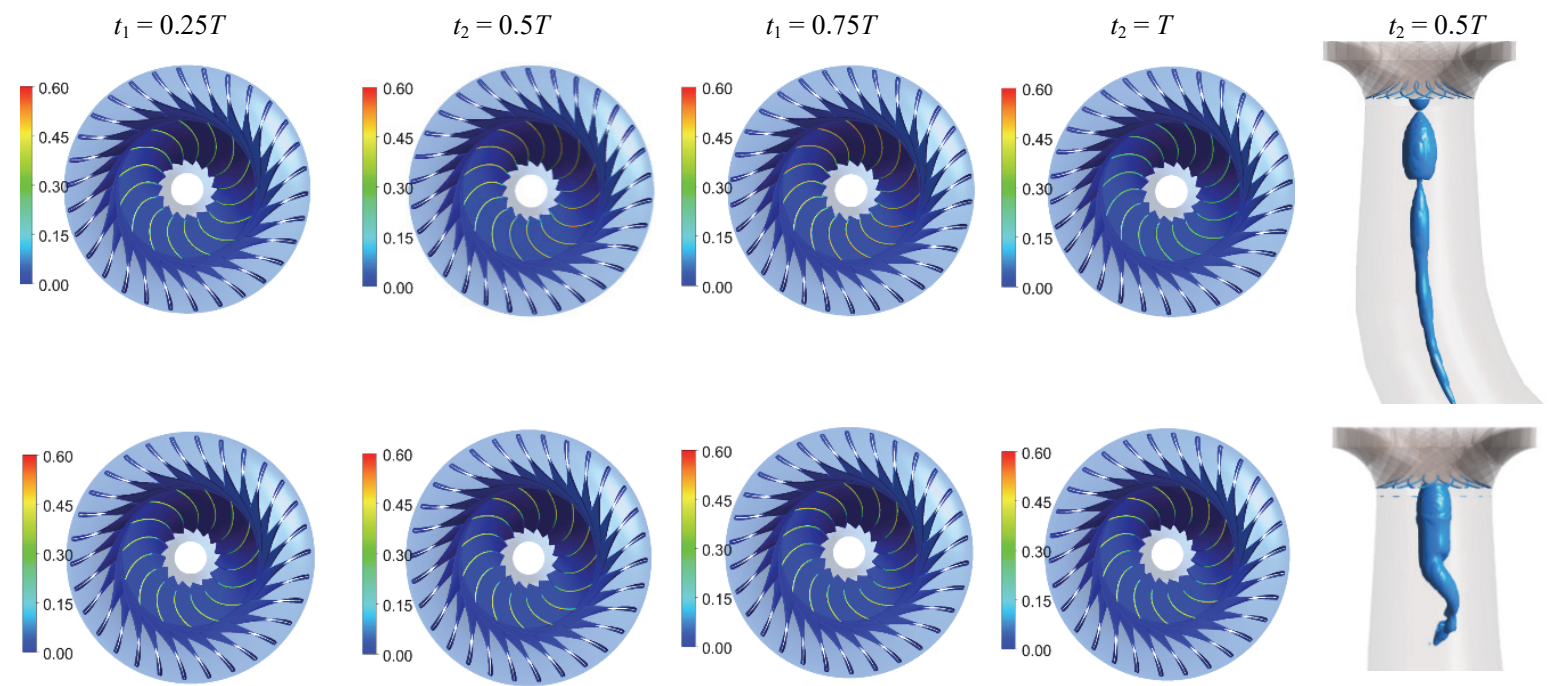

Figure 10 Cavitation on the runner blades in one vortex rope cycle under $\mathrm{HL}$ (above, $\sigma=0.033$ ) and $\mathrm{PL}$ (below, $\sigma=0.01$ ) operating points using a runner with splitter blades.
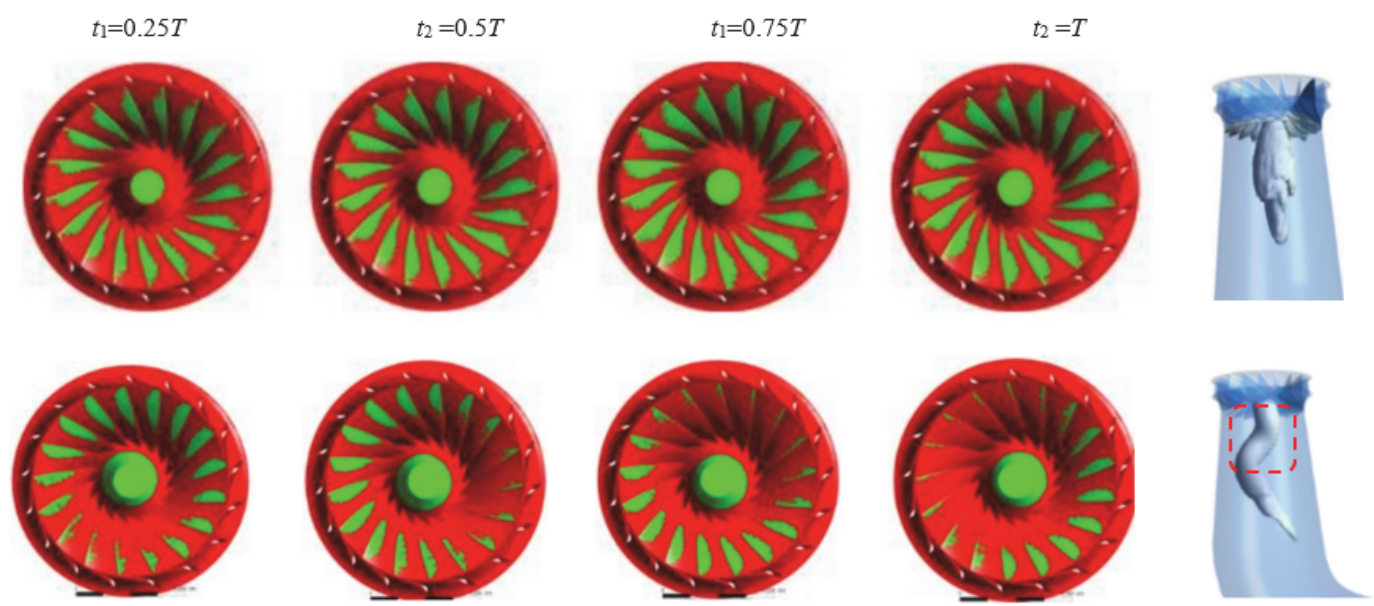

Figure 11 Cavitation on the runner blades in one vortex rope cycle under $\mathrm{HL}$ (above, $\sigma=0.025$ ) and $\mathrm{PL}$ (below, $\sigma=0.01$ ) operating points using a traditional runner [2]. 

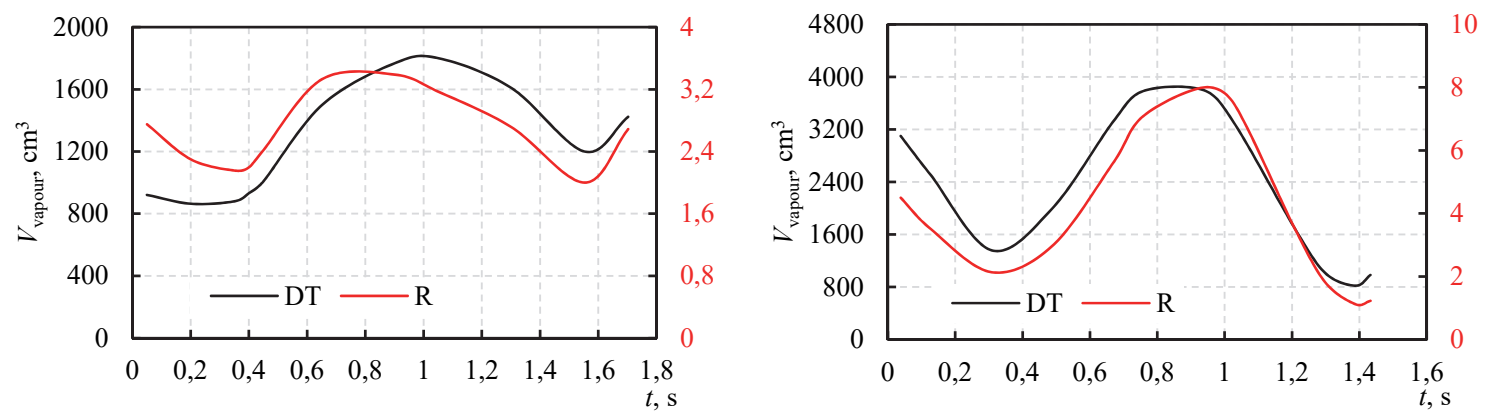

Figure 12 Volume of vapor on draft tube (DT) and runner (R) under PL (left) and HL (right) conditions.

The cavitating rope evolutions also disclosed the pressure fluctuation in the draft tube. The pressure monitoring point was set near the draft tube inlet (DT5). The amplitude-frequency spectra of pressure fluctuations under off-design conditions are obtained by fast Fourier transform (FFT), as shown in Figs. 13 and 14. In both cases (PL and $\mathrm{HL}$ ), the rough pressure peaks appear at the frequency $f_{\mathrm{n}}=29.55 \mathrm{~Hz}$ and $f_{\mathrm{n}}=16 \mathrm{~Hz}$ caused by the influence of the 30 blades and 15 splitter blades in the runner, respectively. Furthermore, the results showed that the rough pressure peaks at the frequency 0.2 and 0.7 times the rotational frequency also appeared near the runner outlet. This was caused by the unstable behavior of the cavitating vortex rope $[27,28]$ with the "cut wave" phenomenon that occurs at a critical cavitation number [29].

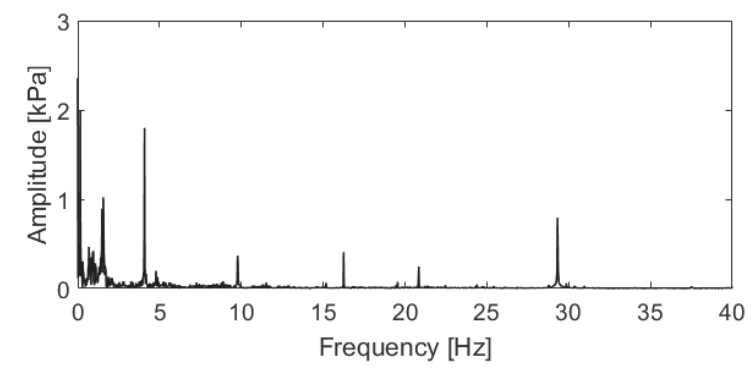

Figure 13 Pressure fluctuation frequency for the PL condition from cavitating flow analysis $(\sigma=0.01)$ at DT5 monitor pressure point

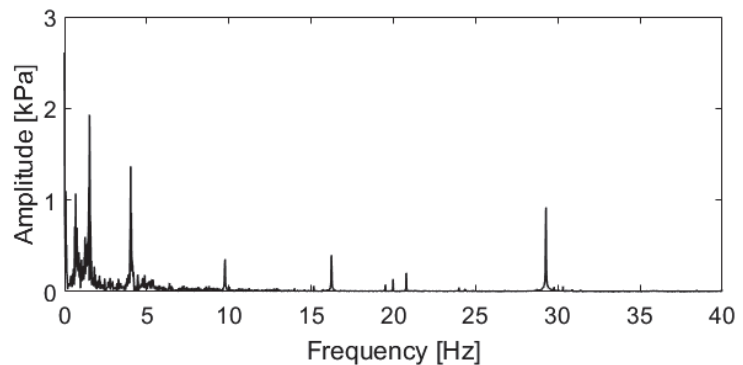

Figure 14 Pressure fluctuation frequency for the $\mathrm{HL}$ condition from cavitating flow analysis $(\sigma=0.033)$ monitor pressure point.

\section{CONCLUSIONS}

In this study, transient simulations with the SST turbulence model and Zwart cavitation model were performed at off-design conditions in a Francis-99 turbine. The results show that under critical cavitation the cavitating rope structure at near runner outlet in the draft tube was straight cylinder-shape before changes and becomes a spiral-shape and columnar-shape at PL and HL operating points. The analysis by VTE shows that the vortex dilatation and baroclinic torque term only happened at the zones of high vapor volume fraction, and the almost vorticities were produced by vortex stretching term. The vorticity distribution seems symmetrical at near runner outlet in draft tube inlet zone with the splitter blades runner.

For both the HL and PL operating points, the cavity zone on different blades was almost axisymmetric, which revealed that the Francis turbine with splitter blades is more improved cavitation performance. The results provide further proper documentation of the behavior of Francis turbine with splitter blades runner.

\section{REFERENCES}

[1] Rheingans, W. (1940). Power swings in hydroelectric power plants. Transactions of the ASME, 62, 171-184.

[2] Yang, J., Zhou, L. J., \& Wang, Z. W. (2015). The numerical research of runner cavitation effects on spiral vortex rope in draft tube of Francis turbine. Journal of Physics: Conference Series, 656, 012076. https://doi.org/10.1088/1742-6596/656/1/012076

[3] Yang, J., Zhou, L. J., \& Wang, Z. W. (2016). The numerical simulation of draft tube cavitation on Francis turbine at offdesign conditions. Engineering with Computers, 33, 139155. https://doi.org/10.1108/EC-12-2014-0257

[4] Kubota, K. \& Watanabe, S. (2006). Advantages of Splitter Runner Applied to Ultra High-Head and Large-Capacity Pump-Turbines. $23^{\text {rd }}$ IAHA Symposium on Hydraulic Machinery and Systems, Yokohama.

[5] Kergourlay, G., Younsi, M., Bakir, F., \& Rey, R. (2007). Influence of Splitter Blades on the Flow Field of a Centrifugal Pump: Test-Analysis Comparison. International Journal of Rotating Machinery, Vol. 2007, ID: 85024, pp. 13. https://doi.org/10.1155/2007/85024

[6] Zhang, H. M. \& Zhang, L. X. (2013). Numerical investigation of cavitating turbulent flow in a Francis turbine runner fitted with splitter blades. Advanced Materials Research, Vol. 662, 637-642. https://doi.org/10.4028/www.scientific.net/AMR.662.637

[7] NTNU, Francis-99 workshops 2. Experimental data for a high head Francis turbine model at several operating points. http://www.ltu.se/research/subjects/Stromningslara/Konfer enser/Francis-99 (accessed 27.05.2016).

[8] Cervantes, M. J., Trivedi, C., Dahlhaug, O. G., \& Nielsen, T. (2015). Francis-99 Workshop 1: Steady operation of Francis turbines. Phys. Conf. Ser. 579, 011001. https://doi.org/10.1088/1742-6596/579/1/011001

[9] Trivedi, C., Cervantes, M. J., \& Dahlhaug, O. G. (2016). Experimental and Numerical Studies of a High-Head Francis Turbine: A Review of the Francis-99 Test Case. Energies, 9(2), 74. https://doi.org/10.3390/en9020074

[10] Gavrilov, A. A., Sentyabov, A. V., Dekterev, A. A., \& Hanjali, K. (2017). Vortical structures and pressure pulsations in draft tube of a Francis-99 turbine at PL: RANS 
and hybrid RANS/LES analysis. International Journal of Heat and Fluid Flow, 63, 158-171. https://doi.org/10.1016/j.jiheatfluidflow.2016.05.007

[11] Goyal, R., Cervantes, M. J., \& Gandhi, B. K. (2017). Vortex Rope Formation in a High Head Model Francis Turbine. Journal of Fluids Engineering, 139, 041102-1. https://doi.org/10.1115/1.4035224

[12] Buron, J. D., Houde, S., Lestriez, R., \& Deschênes, C. (2015). Application of the non-linear harmonic method to study the rotor-stator interaction in Francis-99 test case. Journal of Physics: Conference Series, 579, 012013. https://doi.org/10.1088/1742-6596/579/1/012013

[13] Zwart, P., Gerber, A., \& Belamri, T. (2004). A two-phase flow model for predict ing cavitation dynamics. In: Fifth International Conference on Multiphase Flow, Yokohama, Japan, 152.

[14] Menter, F. R. (1994). Two Equation Eddy Viscosity Turbulence Models for Engineering Applications. AIAA J, 32(8), 1598-1605. https://doi.org/10.2514/3.12149

[15] Tamura, Y., Tani, K., \& Okamoto, N. (2014). Experimental and numerical investigation of unsteady behavior of cavitating vortices in draft tube of low specific speed Francis turbine. 27 $27^{\text {th }}$ IAHR Symposium on Hydraulic Machinery and Systems, 2.2.6. https://doi.org/10.1088/1755-1315/22/3/032011

[16] Zhao, Y., Liao, W., Ruan, H., Luo, X. (2015). Performance study for Francis-99 by using different turbulence models. Journal of Physics: Conference Series, 579(1), 012012. https://doi.org/10.1088/1742-6596/579/1/012012

[17] Gavrilov, A., Dekterev, A,. Minakov, A., Platonov, D., \& Sentyabov, A. (2017). Steady state operation simulation of the Francis-99 turbine by means of advanced turbulence models. Phys. Conf. Ser. 782, 012006. https://doi.org/10.1088/1742-6596/782/1/012006

[18] Wack, J. \& Riedelbauch, S. (2016). Two-phase simulations of the full load surge in Francis turbines. IOP Conference Series: Earth and Environmental Science, 49, 092004. https://doi.org/10.1088/1755-1315/49/9/092004

[19] Minakov, A., Platonov, D., Sentyabov, A., \& Gavrilov, A. (2017). Francis-99 turbine numerical flow simulation of steady state operation using RANS and RANS/LES turbulence model. Phys. Conf. Ser., 782: 012005. https://doi.org/10.1088/1742-6596/782/1/012005

[20] Trivedi, C., Cervantes, M. J., Gandhi, B. K., \& Dahlhaug, O. G. (2013). Experimental and numerical studies for a high head francis turbine at several operating points. Journal of Fluids Engineering, 135(11), 111102. https://doi.org/10.1115/1.4024805

[21] Trivedi, C., Cercantes, M. J., \& Gandhi, B. K. (2016). Investigation of a High Head Francis Turbine at Runaway Operation Conditions. Energies, 9(3), 149. https://doi.org/10.3390/en9030149

[22] Goyal, R., Trivedi, C., Gandhi, B. K., \& Cervantes, M. J. (2017). Numerical Simulation and Validation of a High Head Model Francis Turbine at PL Operating Condition. Inst. Eng. India Ser. 99(5), 557-570. https://doi.org/10.1007/s40032-017-0380-z

[23] Hunt, J. C. R., Wray, A. A., \& Moin, P. (1988). Eddies, streams, convergence zones in turbulent flows. Proceedings of the Summer Program 1988 in its Studying Turbulence Using Numerical Simulation Databases. California, USA, 2, 193-208.

[24] Kobro, E. (2010). Measurement of Pressure Pulsation in Francis Turbines. PhD thesis, Norwegian University of Science and Technology (NTNU), Trondheim, Norway.

[25] Yu, A., Luo, X., \& Ji, B. Numerical simulation and analysis of the internal flow in a Francis turbine with air admission. IOP Conf. Series: Materials Science and Engineering, 72015, 72, 042047. https://doi.org/10.1088/1757-899X/72/4/042047
[26] Ji, B., Xianwu, L., Arndt, R. E. A., \& Yulin, W. (2014). Numerical simulation of three dimensional cavitation shedding dynamics with special emphasis on cavitationvortex interaction. Ocean Engineering, 87, 64-77. https://doi.org/10.1016/j.oceaneng.2014.05.005

[27] Minakov, A. V., Platonov, D. V., Dekterev, A. A., Sentyabov, A. V. \& Zakharov, A. V. (2015). The numerical simulation of low frequency pressure pulsations in the highhead Francis turbine. Computers and Fluids, 197-205. https://doi.org/10.1016/j.compfluid.2015.01.007

[28] Ciocan, G. D., Iliescu, M. S., Vu, C. T., Nennemann, B., \& Avellan, F. (2007). Experimental Study and Numerical Simulation of the FLINDT Draft Tube Rotating Vortex, ASME J. Fluids Eng., 129, 146-158. https://doi.org/10.1115/1.2409332

[29] Xu Hongquan, Pan Luoping, Li Fei. (1998). Research on the infuence fractors and model test method of vortex pressure fluctuation. Hydroelectric Eng, 1998(3), 52-58 (in Chinese).

\section{Contact information:}

\section{CongTrieu TRAN}

(1) State Key Lab of Water Resources and Hydropower Engineering Science, School of Power and Mechanical Engineering, Wuhan University,

Hubei 430072, China

(2) Hubei Key Laboratory of Waterjet Theory and New Technology,

Wuhan University,

Wuhan 430072, China

(3) National University of Civil Engineering,

55 Giai Phong, Hanoi, Vietnam

\section{Bin JI}

(1) State Key Lab of Water Resources and Hydropower Engineering Science, School of Power and Mechanical Engineering,

Wuhan University,

Hubei 430072, China

(2) Hubei Key Laboratory of Waterjet Theory and New Technology,

Wuhan University,

Wuhan 430072, China

\section{Xinping LONG}

Corresponding Author

(1) State Key Lab of Water Resources and Hydropower Engineering Science, School of Power and Mechanical Engineering,

Wuhan University,

Hubei 430072, China

(2) Hubei Key Laboratory of Waterjet Theory and New Technology, Wuhan University,

Wuhan 430072, China

E-mail: xplong@whu.edu.cn 